\author{
Aparecido Carlos Gonçalves \\ cido@dem.feis.unesp.br \\ University of the State of Sao Paulo \\ Faculty of Engineering of Ilha Solteira \\ Mechanical Engineering Department \\ 15385-000 Ilha Solteira, São Paulo, Brazil \\ João Batista Campos Silva \\ jbcampos@dem.feis.unesp.br \\ University of the State of Sao Paulo \\ Faculty of Engineering of Ilha Solteira \\ Mechanical Engineering Department \\ 15385-000 Ilha Solteira, São Paulo, Brazil
}

\section{Predictive Maintenance of a Reducer with Contaminated Oil under an Excentrical Load through Vibration and Oil Analysis}

Among all Predictive Maintenance techniques the oil analysis and vibration analysis are the most important for monitoring some systems. The integration of these techniques has the potential to revolutionize industrial practices and provide a large economic gain for industries. To study the integration of both techniques a bench test was set up and put to work to the extreme limit of use. Tests were carried out with the lubricant recommended by the manufacturer of the equipment, using lubricants supplemented with various percentages of liquid contaminant and lubricants supplemented with several percentages of solid contaminant. This paper presents the results of the first test, that is, with the oil recommended by the manufacturer in extreme conditions. From the results it was observed that if in a system an abnormal occurrence takes place, for example an extra load during a certain period of time, the lubricant analysis can be used together with the vibration analysis to complement it.

Keywords: Predictive Maintenance, oil analysis, vibration analysis, tribology, wear

\section{Introduction}

Among the techniques for Predictive Maintenance of Reducers, the most used are the oil analysis and vibration analysis, and the simultaneous use of both of these provides accurate results about the condition of a system under test.

The principle of the vibration analysis is based on the idea that the structures of the machines excited by the dynamic efforts (power action) give vibrational signs, whose frequency is equal to the frequency of the exciting agents. An imbalance in a machine component will cause increased vibration, once it causes an imbalance in the system and consequent increase in the power. Thus, observing the progression of the level of vibration, it is possible to obtain information on the state of the machine (Cunha, 2005).

The oil analysis enables identifying the first signs of wear of a component. The identification begins with studying the amount of particles, size, shape and composition, which provides accurate information on the conditions of the moving surfaces without having to disassemble the entire set that these parties belong to. These solid particles are generated by the dynamic friction between the parts in contact. According to the study of these particles, the wear situations of the set can be related and attributed to physical and chemical conditions (Barraclough et al., 1999; Anderson and Williams, 1999). The oil analysis is achieved through laboratory techniques involving, reagents, instruments and equipment.

\section{Literature Review and Theory}

\section{Viscosity monitoring}

Viscosity monitoring is an important component of many programs for the analysis of oil. Even small changes in viscosity can cause major damage to the lubrication. The limit of typical industrial oils is set to $5 \%$ for precaution, and $10 \%$ for critical situations, although applications at high loads and extremely critical systems should also have an alarm system. Cunha (2005) constructed the Table 1 below that is a guide for analysis.

Table 1. Effects of viscosity change.

\begin{tabular}{|c|c|}
\hline Significant reduction of viscosity & Significant increase of viscosity \\
\hline $\begin{array}{c}\text { - Loss of the oil film causing excessive wear; } \\
\text { - Increase of mechanical friction causing excessive } \\
\text { consumption of energy; } \\
\text { - Generation of heat due to mechanical friction; } \\
\text { - Internal or external leaks; } \\
\text { - Increased sensitivity for contamination of particle due } \\
\text { to the reduction of the oil film; } \\
\text { - Failure of oil film for high temperatures, high loads or } \\
\text { during starting and stopping. }\end{array}$ & $\begin{array}{c}\text { - Excessive generation of heat resulting in the oxidation of } \\
\text { oil, sludge and development of varnish; } \\
\text { - Gaseous cavitation due to inadequate flow of oil to } \\
\text { pumps and bearings; } \\
\text { - Lack of lubrication due to inadequate oil flow; } \\
\text { - Oil whipping in the radial bearing; } \\
\text { - Excessive consumption of energy to overcome the } \\
\text { friction of fluid; } \\
\text { Poor demulsibility; } \\
\text { - Weak pumping during cold starting. }\end{array}$ \\
\hline
\end{tabular}

When a significant change in viscosity is observed, the root cause of the problem should always be investigated and corrected. Changes in the viscosity can result from a change in the basic chemistry of the oil (a change in the molecular structure of the oil), or due to ingression of contaminants. Change in viscosity requires additional testing, such as: number of acids (AN) and infrared spectroscopy with the Fourier transform (FTIR) to confirm the incipient oxidation; contaminant tests to identify the presence of 
water or soot, or another less commonly used test, which is the gas chromatography test (GC) to identify any changes in the basic chemistry of the oil (Lantos and Lantos, 2002; Modern, 2001; Parker, 2000).

\section{Physical tests}

The most common physical tests used with spectrographic programs and analysis programs of wear metals are: viscosity, total acid number (TAN) and determination of the water rate.

The method ASTM D445 is used for identification of viscosity, the method ASTM D 974 or D 664 is to determine the total number of acids and ASTM D 1744 to determine the water concentration by titration. In cases where the water is at levels above 0.05 vol.\%, infrared spectrography can be used. Although the limits of control for each of these parameters need to be adjusted depending on the type of lubricant and equipment, variations in viscosity of $\pm 10 \%$, TAN greater than $3 \mathrm{mg} / \mathrm{g}$, and water exceeding 100 to $500 \mathrm{ppm}$ are usually sufficient for an intervention or at least for further investigation (Lockwood and Dalley, 1992; Author et al., 2006).

\section{Ferrography}

The ferrographic techniques are divided into two levels of analysis. A quantitative one, which is an evaluation technique of the wear conditions of the components of a machine, by quantifying the particles in suspension in the lubricant, and an analytical one, which uses the observation of particles in suspension in the lubricant.

The quantitative ferrography is also known as direct reading ferrography. This one measures the concentration of ferrous particles in a fluid sample. With this technique one can get information on the degree of severity of wear in the machine under analysis.

The PQA (particle quantifier automatic) is a type of device for direct ferrography where an index that represents the magnetic density in a given volume of lubricant is measured (Author et al.. 2006 and Author et al., 2007).

When the quantitative ferrography indicates an abnormal wear tendency, the analytical ferrographic techniques can be used to specifically identify the nature of the machine's potential problems. This enables a thorough study of particles whose size is between 1 and $250 \mu \mathrm{m}$. A ferrogram is built and then it can be analyzed aided by optical and electron microscopy, identifying the morphology of the particles, hence identifying any anomaly.

The ferrograms consist of transparent slides where the magnetic particles are deposited, they are separated by sizes by means of a magnetic field, other particles are randomly placed in the "barriers" formed by magnetic particles.

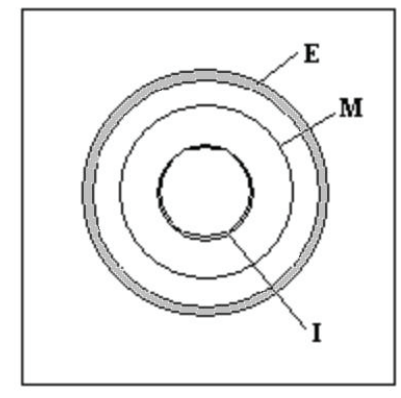

Figure 1. Obtaining the ferrogram.

In Fig. 1 it is presented the RPD (rotary particle depositor) that extracts wear debris from a carrier fluid by the action of magnetic, centrifugal and gravitational forces on the debris. This debris is deposited onto a substrate in form of three concentric rings termed the middle, inner and outer rings. During the deposition process the wear debris also undergoes a sizing operation in that the inner ring will contain a full particle size range, the middle ring intermediate and small sized particles and the outer ring small sized particles.

\section{Study of Vibrations}

From the analysis of vibration signals it is possible to make decisions whether or not to intervene in the operation of the machine, so that it can be "available" as much as possible, reducing maintenance costs, time-stop of the machine, reducing the stock and improving safety, among others.

Thus, it is possible from the vibration signs at certain points of the equipment, to identify the emergence of new dynamic efforts or the abrupt increase of the magnitude of the response, which are indicators of the appearance of defects or deterioration of the operation.

Vibration data can be measured with accelerometers and processed by a signal analyzer. The signal can be analyzed in the time domain or in the frequency.

The fast Fourier transform (FFT) can derive a wave form in time and present it in the frequency domain as shown in Fig. 2. This process is the breaking of all vibrational signals into individual components of the vibration signal and plotting it in a frequency scale. This signal in the frequency domain is called frequency spectrum and provides valuable information about the condition of a machine (Grenn, 2003).

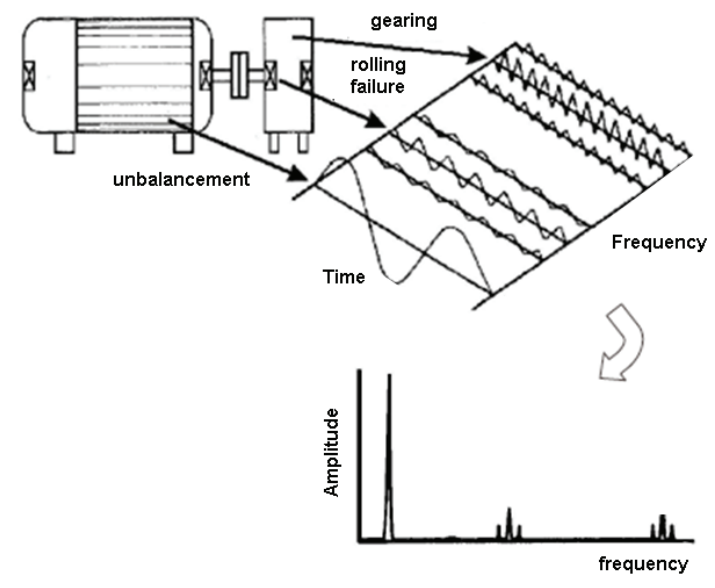

Figure 2. Vibratory signal in the frequency domain.

The frequency spectra are used to obtain information that help determine the location of the problem, the cause of the problem and the time for the problem to become critical. This depends on the type of machine and is always relative to the level of vibration of the machine's proper operation. The frequency at which the vibration occurs indicates the type of failure and it provides an indication of what is causing the failure.

In the case of application for predictive maintenance, the international technical standards, including the ISO, define two criteria for the adoption of a global value. One method assesses the severity of vibration by absolute measurement of non-rotating parts. The other one assesses conditions of the machine by direct measurement of oscillation of the shaft (Parker, 2000).

According to NBR 10082 (1987), a rating of acceptable levels of vibration severity for similar machines is established and grouped into classes. Table 2 shows the guidance offered by this standard, where: 
Class I - Small machines activated by directly coupled electric motor, maximum power of $15 \mathrm{~kW}$.

Class II - Mid-sized machines, class I type, with power greater than $15 \mathrm{~kW}$, up to $75 \mathrm{~kW}$. Motors or machines rigidly mounted up to $300 \mathrm{KW}$.
Class III - Large driving machines and other large machines $(>75$ $\mathrm{kW}$ ) with rotating masses mounted on rigid and heavy foundations, which are relatively rigid in the measuring of vibration.

Class IV - Machines of the Class III type, mounted on relatively flexible foundations in the measuring of vibration, for example, a set of turbogenerators.

Table 2. Classification and assessment of machines by vibration severity levels.

\begin{tabular}{cccccc}
\hline \multicolumn{2}{c}{ Range of vibration severity } & \multicolumn{5}{c}{ Avaliation of quality for differents machine classes } \\
\hline \multirow{2}{*}{ Range } & $\begin{array}{c}\text { Vebcity in limits } \\
\text { (mmis) }\end{array}$ & Clas I & Class II & Clas III & Chs IV \\
\hline 0,28 & 0,28 & A & A & A & A \\
0,45 & 0,45 & A & A & A & A \\
0,71 & 0,71 & A & A & A & A \\
1,12 & 1,12 & B & A & A & A \\
1,8 & 1,8 & B & B & A & A \\
2,8 & 2,8 & C & B & B & A \\
4,5 & 4,5 & C & C & B & B \\
7,1 & 7,1 & D & C & C & B \\
11,2 & 11,2 & D & D & C & C \\
18 & 18 & D & D & D & C \\
28 & 28 & D & D & D & D \\
45 & 45 & D & D & D & D \\
71 & upper 45 & D & D & D & D \\
\hline
\end{tabular}

Where: $A=$ Proper conditions; $B=$ Acceptable for continued operation; $C=$ Tolerable limit; $D=$ Non-permissible.

For rotating machines with rotation speeds in the range of 600 to $12,000 \mathrm{rpm}$ (10 to $200 \mathrm{~Hz}$ ), ISO standard 2372, VDI Richiline 2056, and in Brazil - NBR 10082, take the value of effective vibration speed, known as rms speed of the signal, as the unit of measure for identifying the severity of vibration.

The parameter to be measured is the absolute velocity of vibration on the machine parts, preferably the bearings. In this case, the global value chosen as the unit of measure to indicate the vibration severity, the effective value, or simply RMS speed (Vef) is not represented by a single scale of values. This is due to the great diversity of forms, mass, assembly and operational conditions of the equipment, which results in the RMS speed values for different levels of acceptable severity.

In more complex situations, where there is a combination of more than one source of excitement added to the noise transmitted through the support and foundations of the machines, the obtained spectrum of frequencies can present difficulties in the analysis (Cunha, 2005).

In cases like this it is necessary to use other more dedicated techniques, such as the technique of demodulation, which enables identifying noise sources responsible for the excitation of resonant responses in the structure. Hence, allowing to monitor defects that are responsible for impacts of the repeated excitation type, in addition to others that produce modulator signals, even if the level of energy of the source does not allow a direct identification of its frequency in the general spectrum, as it generates amplitudes of minor significance, which remain hidden in the level of background noise.

Taking into consideration, by generalization, that the modulation in magnitude of a signal is defined as the multiplication of one sign for another, a nonlinear inherent process that creates new frequencies are not present in any of the signals involved. The identification of the noise source associated with the defect requires identifying the frequency of the modulating signal (Parker, 2000).

The process of identifying the modulating frequency of a modulated signal is known as demodulation, and includes the following steps (Cunha, 2005): a) Filtering of the signal by band-pass filter for the frequency range identified as modulated;

b) Detection of the modulator signal;

c) Spectral analysis of this detected modulator signal.

\section{Material and Methods}

In this work, to verify the effectiveness of the techniques studied, a reducer of the worm drive type was monitored. For this monitoring a bench test was built, where the reducer, coupled with its entry shaft to an electric motor, by means of an elastic coupling, had a load of an unbalanced mass in its output shaft.

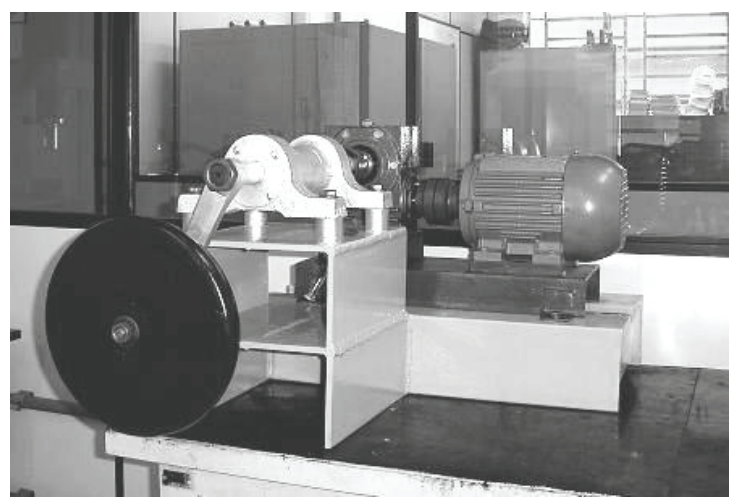

Figure 3. Bench test for verification of the studied techniques.

A photograph of the bench is shown in Fig. 3. The electric motor used is a WEG, $220 \mathrm{~V}, 60 \mathrm{~Hz}$, three-phase power with $0.5 \mathrm{CV}$ power and $1720 \mathrm{rpm}$.

The reducer used was a Macopema, ZM reducer, worn thread, with a reduction of $1: 30,0.53 \mathrm{CV}$ at the entry and $0.31 \mathrm{CV}$ at the output, with oil capacity of 0.25 liters.

At the output of the reducer a bearing was attached and after the bearing a $7.5 \mathrm{~kg}$ mass with a $195 \mathrm{~mm}$ arm. 
The preferred vibration frequencies of the reducer analyzed were calculated, as illustrated in Table 3.

Table 3. Preferred vibration frequencies of the reducer.

\begin{tabular}{|c|c|c|c|c|c|}
\hline \multicolumn{3}{|c|}{ Rolling element bearing (www.skf.com) } & \multirow{2}{*}{\multicolumn{2}{|c|}{ Shaft rotation }} & \multirow[b]{2}{*}{ Engagement } \\
\hline \multicolumn{3}{|c|}{\begin{tabular}{|c|c|c|} 
Model & 6008 & 6204 \\
\end{tabular}} & & & \\
\hline $\mathrm{f}_{\mathrm{ip}}$ & $197 \mathrm{~Hz}$ & $142 \mathrm{~Hz}$ & exit & entry & \multirow{4}{*}{$28.67 \mathrm{~Hz}$} \\
\hline$f_{e p}$ & $147 \mathrm{~Hz}$ & $87.5 \mathrm{~Hz}$ & \multirow{3}{*}{$0.95 \mathrm{~Hz}$} & \multirow{3}{*}{$28.67 \mathrm{~Hz}$} & \\
\hline $\mathrm{f}_{\mathrm{rp}}$ & $191 \mathrm{~Hz}$ & $114 \mathrm{~Hz}$ & & & \\
\hline$f_{g p}$ & $13.2 \mathrm{~Hz}$ & $11 \mathrm{~Hz}$ & & & \\
\hline
\end{tabular}

Where: fip = defect frequency of inner race; fep = defect frequency of outer race; frp = defect frequency of rolling element bearing; fgp = defect frequency of cage.

The tests were conducted after a running period of 168 hours, for four weeks, and in each week (168 hours) oil samples were collected.

Oil recommended by the manufacturer was used; beyond oil with several percentages of liquid contamination and oil with various percentages of solid contamination.

This work presents results obtained from the first four weeks of testing, with ISO 320 oil that was recommended by the manufacturer of the reducer.

The vibration measurements were collected in the three directions of the reducer. Analyses were performed in time and frequency in order to determine the beginning and severity of the active wear where the sensors were placed for collection of the vibration signs. Figure 4 shows the points along the reducer where the sensors were placed for collection of the vibration signs.

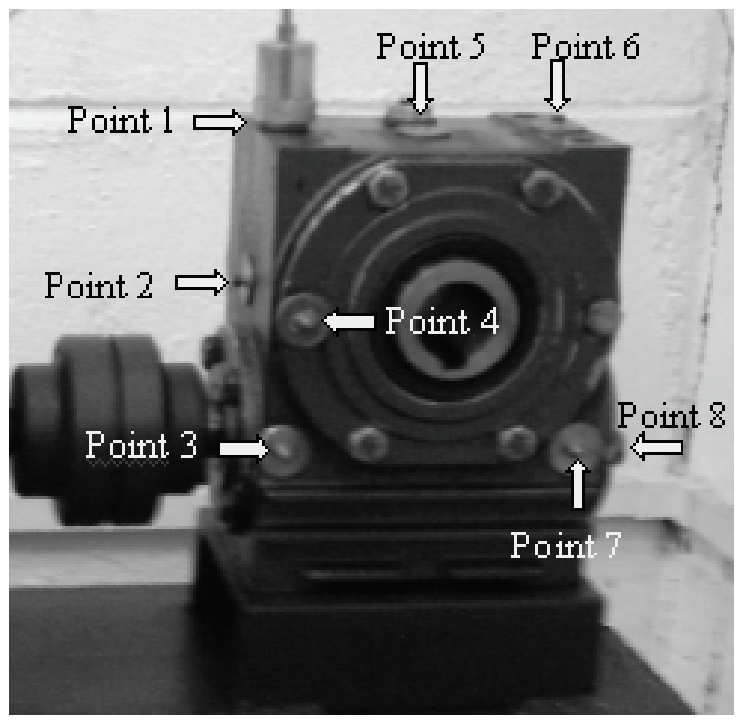

Figure 4. Collection points of vibration signals.

According to the standards, the bearings should be monitored first, thus points 3 and 7 were chosen. Points 2 and 5 represent the other two directions. These points contain all the information provided by points $1,4,6$ and 8 .

The time vibration signals were obtained by measuring the vibration speed of the reducer. For such measures piezoelectric accelerometers, a 4-channel Conditioner/Amplifier, data acquisition system DaqBooK and a Notebook were used. The sampling frequencies were of $500 \mathrm{~Hz}, 1 \mathrm{kHz}, 5 \mathrm{kHz}$ and $10 \mathrm{kHz}$, and the corresponding analog filters were of $141 \mathrm{~Hz}, 281 \mathrm{~Hz}, 2250 \mathrm{~Hz}$ and $4500 \mathrm{kHz}$. For each frequency 10 samples were taken out of 2048 points.

The time vibration signals obtained were processed using the algorithm FFT (Fast Fourier Transform), and analyzed in the laboratory through the "software" DASYlab.
As the accelerometer measures the vibration speed of the reducer, using a reading indicator, the measured value of greatness is obtained directly, that is, the value of the effective vibration speed for each distinct sampling frequency. The value of the vibration severity, however, is obtained when a vibration signal of a sampling frequency of $5000 \mathrm{~Hz}$ is read, but subjected to a high-passed filter of $10 \mathrm{~Hz}$ and a low-passed of $1000 \mathrm{~Hz}$. Both the effective value of the vibration speed and the severity of vibration were obtained using the "software" DASYlab, which contains numerous tools as: reading indicators, filters, etc.

The vibration analysis was achieved by spectral analysis, the values of the effective vibration speed and vibration severity.

Oil samples were prepared in the rotary particle depositor (RPD), and then examined and photographed using the optical microscope Neophot 21 with adapted light transmitted. In the RPD lamina the particles are arranged in three separate rings, depending on the size of the particle, due to this, it was necessary to capture the images by observing these three rings separately.

Using the automatic monitor of ferrous particles, the PQ index of the samples was obtained. Also the viscosity, water content, the total acid number and atomic absorption of the oil samples were obtained at the end of each test.

\section{Results and discussions}

\section{Analysis of lubricant}

Initially, the inner elements of the reducer were photographed for a subsequent comparison and verification of wearing as in Fig. 5.
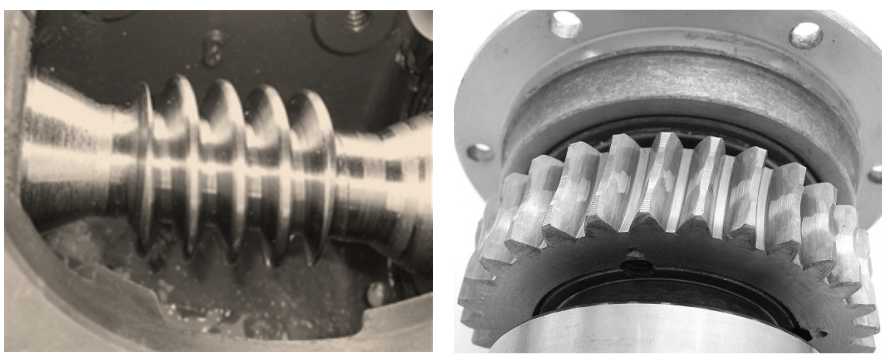

Figure 5. Inner elements of the reducer. On the left is the worn screw and on the right the crown gear.

Figures $6,7,8$ and 9 show the photographs of particles after each experiment during the four weeks. Different from solid contamination (not presented in this paper), there were no notable evolution of wear during the four weeks. It was common to observe the same type of particle after each experiment; that is, some particles observed in the first week were also seen in the second, third or fourth ones.

In Fig. 6 it can be seen severe wear particles (first photo) and bronze particles (second one), and in Fig. 7 it can be seen cutting particles. 


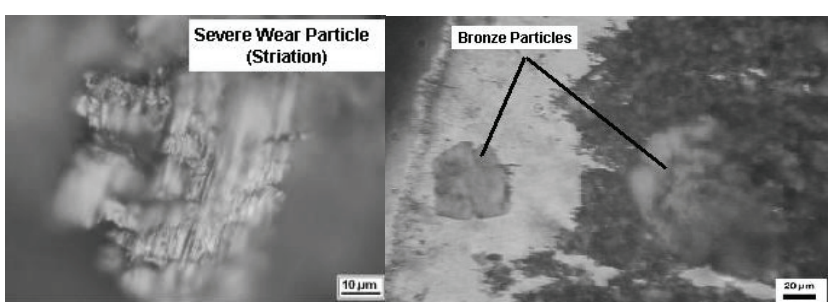

Figure 6. Wear particles generated in the first week of the first experiment with transmitted and reflected light. First picture: inner ring of the RPD. Second picture: outer ring.

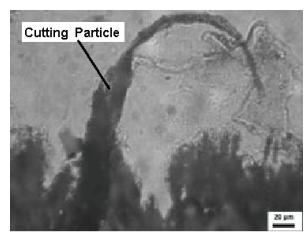

Figure 7. Wear particles generated in the second week of the first experiment with transmitted and reflected light in the intermediated ring of RPD.

In Fig. 8 it can be seen bronze detained between the ferrous particles (first photo) and on the parts difficult to focus (second photo). And in Fig. 9 it can be seen the presence of oxide (first photo) and laminar particle (second photo).

Table 4 presents the tests' values of TAN, viscosity at $400^{\circ} \mathrm{C}$ and $1000^{\circ} \mathrm{C}$, after the end of the last week of the first experiment. Table 5 shows the result of the atomic absorption at the end of this experiment.
Table 6 shows the values obtained in the direct ferrography during the experiments, represented by the PQ index of the magnetic particles counter. Figure 10 shows the state of the reducer after the experiments.

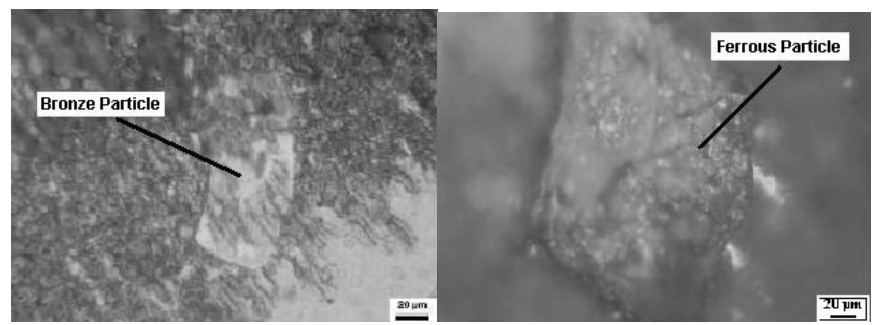

Figure 8. Wear particles generated in the third week of the first experiment with reflected and transmitted light in the intermediary ring of RPD.

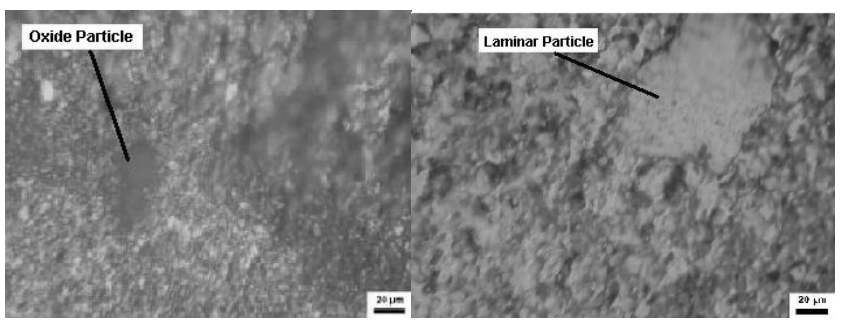

Figure 9. Wear particles generated in the fourth week of the first experiment. The first photo is of the inner ring of RPD observed with transmitted and reflected light. The second photo is of the outer ring with the same lights.

Table 4. Tests conducted on the oil at the end of the experiment.

\begin{tabular}{|c|c|c|c|}
\hline Water & TAN & Viscosity at $40^{\circ} \mathrm{C}$ & Viscosity at $100^{\circ} \mathrm{C}$ \\
\hline ASTM D 95 & ASTM D 664 & ASTM D445 & ASTM D 445 \\
\hline$(\%)$ & $\mathrm{mg} \mathrm{KOH} / \mathrm{g}$ & $\mathrm{cSt}$ & $\mathrm{cSt}$ \\
\hline 0,00 & 1.17 & 295 & 42 \\
\hline
\end{tabular}

Table 5. Atomic Absorption conducted on the oil at the end of the experiment.

\begin{tabular}{|c|c|c|c|c|c|c|}
\hline \multicolumn{7}{|c|}{ Atomic absorption } \\
\hline $\mathrm{Cu}$ & $\mathrm{Si}$ & $\mathrm{Al}$ & $\mathrm{Fe}$ & $\mathrm{Pb}$ & $\mathrm{Cr}$ \\
\hline $\mathrm{ppm}$ & $\mathrm{ppm}$ & $\mathrm{ppm}$ & $\mathrm{ppm}$ & $\mathrm{ppm}$ & $\mathrm{ppm}$ & $\mathrm{ppm}$ \\
\hline 580 & 18 & 4 & 142 & 0 & 0 \\
\hline
\end{tabular}

Table 6. PQ Rates obtained on the particle monitor.

\begin{tabular}{|c|c|c|c|}
\hline \multicolumn{3}{|c|}{ Test A } \\
\hline 1st Sample & 2nd Sample & 3rd Sample & 4th Sample \\
\hline 670 & 1680 & 3050 & 4000 \\
\hline
\end{tabular}



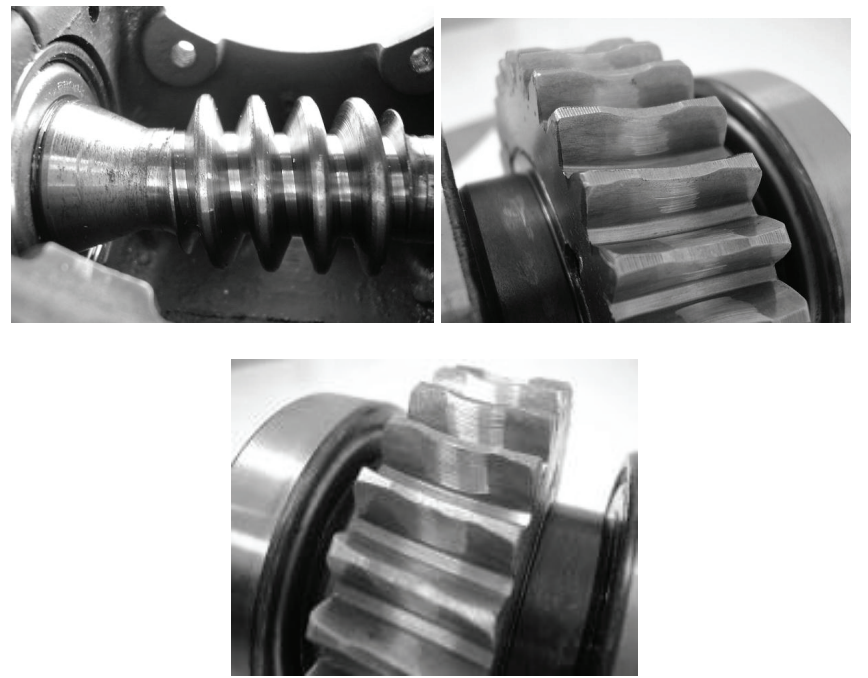

Figure 10. Inner elements of the reducer after the first test (after four weeks).

Through Table 4 it was noticed that the viscosity at $100^{\circ} \mathrm{C}$ increased from allowable range (27.9-33.3), according to the specifications of the new oil (ISO 320), to 42. This means an alert, since the $10 \%$ of the permissible range was exceeded. This may be an indication of oxidation of the oil.

In Table 5 large amounts of $\mathrm{Cu}$ was noticed in the bronze from the crown and $\mathrm{Fe}$ in the alloy steel from which the pinion is manufactured. The $\mathrm{Si}$ is an indicator of external contamination.

In Table 6 the gradual wear of the pinion can be seen. As the samples were not changed during the first experiment, the quantity of metallic particles accumulated during the weeks of this first experiment.

Comparing Fig. 5 with Fig. 10 we can observe that there was, really, a wear during the four weeks of the tests.

\section{Analysis of vibrations}

Several vibration measures were taken at various points of the reducer. In Figs. 11 and 12, some measures taken at some points are presented. Table 7 shows the effective value and the severity value of the vibration velocities.
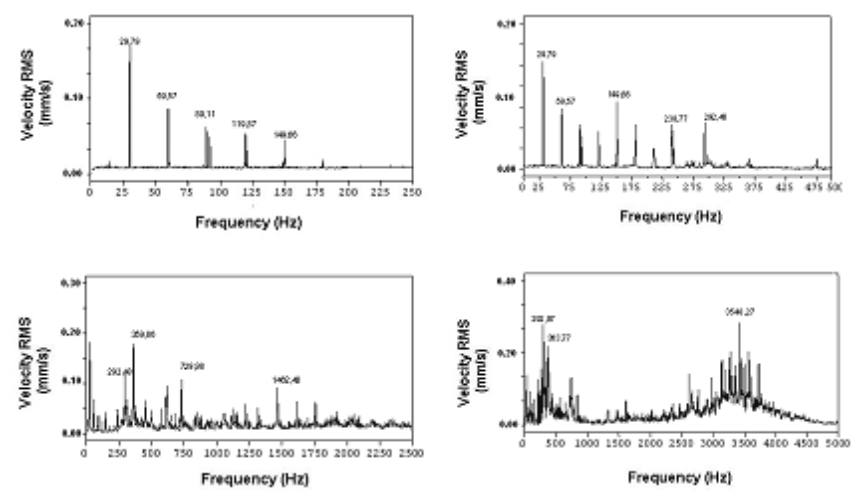

Figure 11. Vibration spectra obtained at point 2 , for sampling frequencies of $500,1000,5000$ and $10000 \mathrm{~Hz}$ with analog filters of 141, 281, 2250 and $4500 \mathrm{~Hz}$, respectively, at the last week of the first experiment.
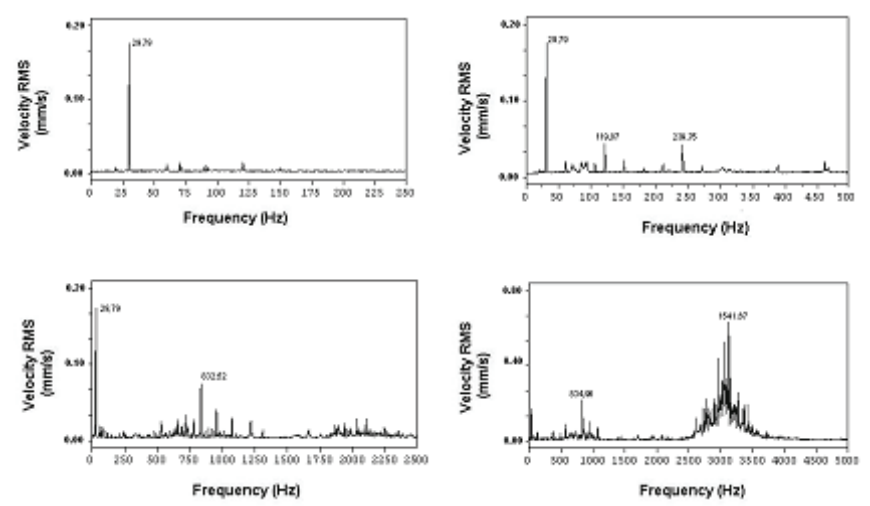

Figure 12. Vibration spectra obtained at point 5, for sampling frequencies of $500,1000,5000$ and $10000 \mathrm{~Hz}$ with analog filters of 141, 281, 2250 and $4500 \mathrm{~Hz}$, respectively, after the last week of the first experiment.

Table 7. Effective value of vibration speeds $(\mathrm{mm} / \mathrm{s})$ and severity values of vibration by the NBR 10082 standard, (10 to $1000 \mathrm{~Hz})$, at the end of the last week of the first experiment.

\begin{tabular}{|l|ccc|c|}
\hline \multirow{2}{*}{} & \multicolumn{3}{|c|}{ Vibration effective value (mm/s) } & Vibration Severity \\
\cline { 2 - 5 } & $500 \mathrm{~Hz}$ & $5000 \mathrm{~Hz}$ & $10 \mathrm{KHz}$ & NBR 10082 \\
\hline Point 2 & 0.27 & 0.71 & 0.99 & 0.64 \\
Point 3 & 0.34 & 0.43 & 0.54 & 0.51 \\
Point 5 & 0.37 & 0.44 & 1.09 & 0.42 \\
Point 7 & 0.51 & 0.64 & 0.68 & 0.61 \\
\hline
\end{tabular}

Figure 13 presents a graph showing the trend of the values obtained in the four weeks of the first test for points 2, 3, 5 and 7.

Considering that our experiment fits in Class I of the NBR 10082 standard, we found that all the values are within the range considered to be in good conditions, that is, within the range A of Table 2.

\section{Conclusions}

The type of reducer used, worn drive, is difficult to analyze because in this case there is a low rotation shaft (exit of the crown, which in our case is of $0.95 \mathrm{~Hz}$ ) and the engagement frequency coincides with the rotation shaft frequency, given that the worn screw has a single entry.
Observing Fig. 13, which represents the evolution of the vibration severity in accordance with the NBR10082 Standard, it is not possible to observe a progressive wear tendency. Also no bearing defects were found in the spectra. It was observed that all the values were within the range considered to be in good conditions of the Class I of the NBR 10082 standard, that is, within the range A of Table 2. After disassembling the reducer it was found out that the axis bearings of the worn screw were loose. The literature shows that the loose bearings are represented by the frequency of the spin axis and its harmonics, which is the same case as the wear. This fact was difficult to check because of the coincidence of such frequencies.

In relation to oil analysis we can say that different of solid contamination (not presented in this paper), there was not a 
notable evolution of wear during the four weeks. It was common to observe the same type of particle after each experiment; that is, some particles observed in the first week were also seen in the second, third or fourth one. However, there was an abnormal wear observed by ferrography as found out in wear debris in the four weeks. Most of the photos showed the presence of many ferrous particles and some bronze particles. We also found out many wear particles by friction (laminar particles) and severe wear particles by sliding, which are particles with striation.

One of the simplest tests, the counting of particles through the automatic monitor of PQA particles, showed a high generation of magnetic particles from the first sample. The atomic absorption performed at the end of each test also provided important information about the tribological condition of the system, where a large amount of copper particles can be noted from the crown and iron resulting from the pinion.

In the studied reducer, the oil analysis showed a certain advantage in relation to the vibration analysis, given that since from the beginning the first one demonstrated the reducer's improper operation, while the vibration analysis was difficult to use, since the rotation shaft and engagement coincided.

Summarizing, we can affirm that there was an incorrect operation applied to the system with the unbalanced load and confirmed analyzing visually the engagement wear before and after the four-week experiments, Fig. 5 and Fig. 10 respectively. That wear was verified by oil analysis through ferrography, viscosity changes, PQ index, TAN and atomic absorption, while the "here used" simple vibration analysis technique was not able to detect it.

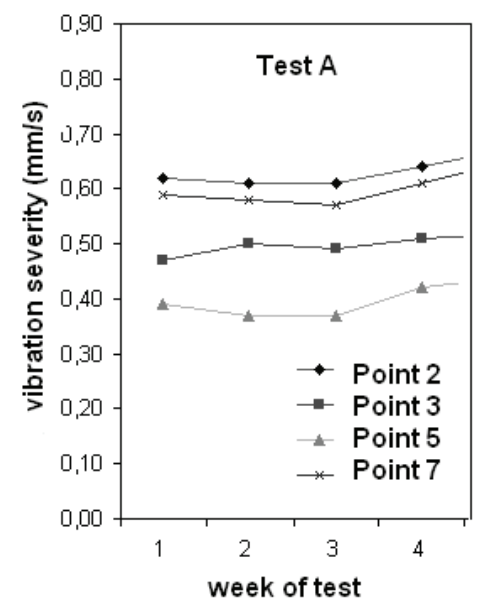

Figure 13. Evolution of the vibration severity in accordance with the NBR 10082 standard.

\section{Acknowledgement}

We thank FAPESP - State of Sao Paulo Research Foundation (Proc.: 2006/07033-8) and CNPq - National Research Council (Edital 015/2007 - UNIVERSAL Faixa C, Proc. 470.117/2007-9) for funding this project and FINEP - Fund for Studies and Projects for forward funds.

\section{References}

Anderson, A., Sweeney, A., Willians, G., 1999, "How to make decisions", In: _ Quantitative approaches to decision making. 9 ed., South Western: College Publishing, 1999, pp. 666-671.

Associação Brasileira de Normas Técnicas - ABNT. NBR 10082: vibração mecânica de máquinas com velocidades de operação de (600 a 12000) rpm - bases para especificação e padrões de avaliação, 1987.

Author et al., 2006, "Maintenance of a reducer by vibration and wear particles analysis", Journal Of Quality In Maintenance Engineering, England, Vol. 12, No. 2, pp. 118-132.

Author et al, 2007, "Vibration and wear Particles Analysis in a test Stand", Industrial Lubrication and Tribology, Vol. 59, issue 5, 2007, ISSN: 0036-8792.

Barraclough T.G., Sperring T.P., Roylance, B.J., Nowell, T., 1999, "Generic-based wear debris identification-on the first step towards morphological classification". In: Proceeding of the International Conference on Condition Monitoring, 1999, Swansea. Proceedings, Oxford: Coxmore Publishing, 1999, pp. 525-538.

Cunha R.C., 2005, "Análise do estado de conservação de um redutor de velocidade através da técnica de partículas de desgaste no óleo lubrificante auxiliada pela análise de vibrações", Dissertação (Mestrado em Engenharia Mecânica) - Faculdade de Engenharia de Ilha Solteira, FEIS, UNESP, Ilha Solteira, $164 \mathrm{p}$.

Grenn A, 2003, "The study of the failure modes of a spur gear using vibration an particle analysis techniques" James Cook University, School of engineering.

Lantos F., Lantos J., Lantos E., 2002, "An unusual twist to the blotter test - the Lantos Method. Practicing Oil Analysis Magazine", Houston, July-August, pp. 46-50.

Lockwood F.E., Dalley R., 1992, "Lubricant analysis. In: Henry, S D. et al. (Ed.). ASM Handbook: friction, lubrication, and wear technology". Metals Park: The Materials Information Society, 1992. Vol. 18, pp. 299-312.

Modern Tribology Handbook, 2001, Vol. I ("Principles of Tribology"), Edited by Bharat Bhushan, CRC Press, 2001

Parker, 2000, "The handbook of hydraulic filtration", Metamora: Parker, 2000, pp. 12-19. 